\title{
Parental Knowledge of Concussion: Evaluation of the CDC's "Heads Up to Parents" Educational Initiative
}

Teresa A. Rice

Follow this and additional works at: https://researchrepository.wvu.edu/etd

\section{Recommended Citation}

Rice, Teresa A., "Parental Knowledge of Concussion: Evaluation of the CDC's "Heads Up to Parents" Educational Initiative" (2018). Graduate Theses, Dissertations, and Problem Reports. 6497.

https://researchrepository.wvu.edu/etd/6497

This Dissertation is protected by copyright and/or related rights. It has been brought to you by the The Research Repository @ WVU with permission from the rights-holder(s). You are free to use this Dissertation in any way that is permitted by the copyright and related rights legislation that applies to your use. For other uses you must obtain permission from the rights-holder(s) directly, unless additional rights are indicated by a Creative Commons license in the record and/ or on the work itself. This Dissertation has been accepted for inclusion in WVU Graduate Theses, Dissertations, and Problem Reports collection by an authorized administrator of The Research Repository @ WVU.

For more information, please contact researchrepository@mail.wvu.edu. 
Parental Knowledge of Concussion: Evaluation of the CDC's "Heads Up to Parents" Educational Initiative

Teresa A. Rice

Dissertation submitted to the College of Education and Human Services at

West Virginia University

in partial fulfillment of the requirements for the degree of

Doctor of Education in

Educational Psychology

Reagan Curtis, Ph.D., Chair

D. Scott Davis, PT, MS, Ed.D., OCS

Patricia Haught, Ed.D.

Dina Jones, PT, Ph.D.

M. Cecil Smith, Ph.D.

Department of Learning Sciences and Human Development

Morgantown, West Virginia

2018

Keywords: sport-related concussion, youth sports, parents, education, CDC Heads UP Copyright 2018 Teresa A Rice 


\title{
ABSTRACT \\ Parental Knowledge of Concussion: Evaluation of the CDC's "Heads Up to Parents" Educational Initiative
}

\author{
Teresa A. Rice
}

Background: A majority of youth club sport organization coaches have well-established concussion knowledge gaps. Potential negative outcomes associated with sport-related concussion drive the need for resources to educate parents about prevention, recognition, and management of concussion in the youth athlete. Parents play a critical role in management of concussion for their child.

Purpose: This study aims to (1) investigate current knowledge of concussion among parents whose children age 5-18 years play a club sport and (2) identify effects of an online video versus online print educational intervention on concussion knowledge change and learning.

Methods: 140 parents whose children played a club sport answered questions regarding their knowledge of sport-related concussion pre and post random assignment to an educational intervention: CDC Concussion Awareness video or CDC Concussion Fact Sheet for Parents. Results: Participating parents demonstrated a moderate level of pre-intervention knowledge (mean=3.73), but critical gaps in knowledge were identified. Knowledge of concussion improved slightly following intervention regardless of intervention type (mean=3.87).

Conclusions: This study confirms the presence of gaps in knowledge of concussion in parents whose children play club sports. Without the protection of concussion legislation, those athletes who participate in club sports are at particular risk due to lack of concussion knowledge and education. This study confirms that education can have a positive impact on parental knowledge of concussion.

Clinical Relevance: Pre-knowledge of concussion is the greatest predictor of post-knowledge of concussion, therefore pre-assessment of target audience knowledge followed by a custom educational intervention taking into account principles of adult learning, would be the most beneficial to increasing concussion knowledge.

Keywords: sports-related concussion, youth sports, parents, education, CDC Heads Up 
Table of Contents

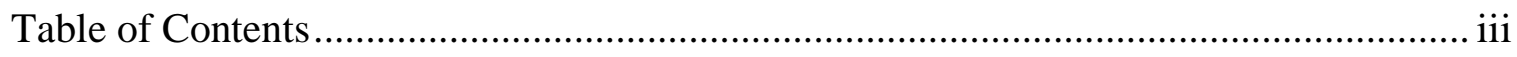

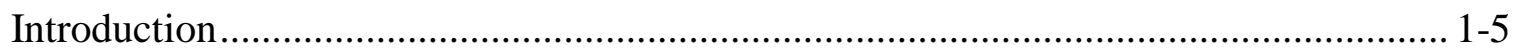

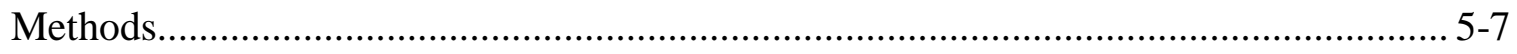

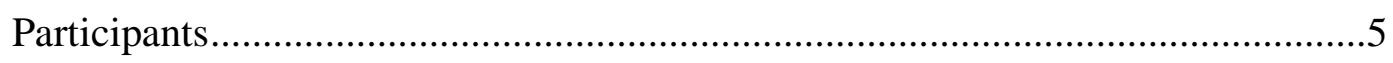

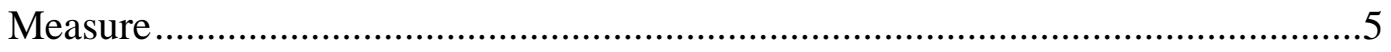

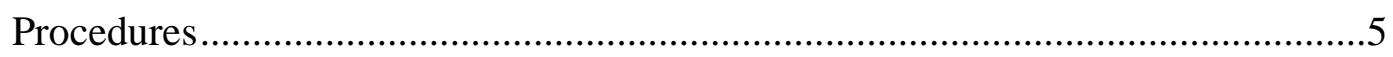

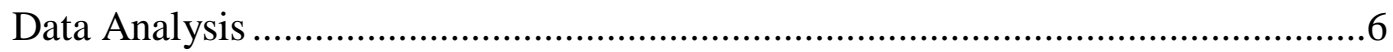

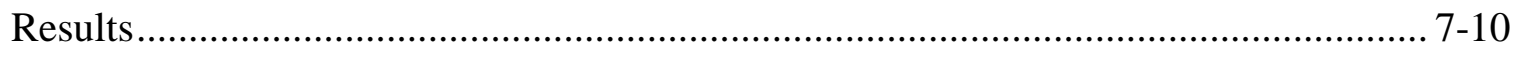

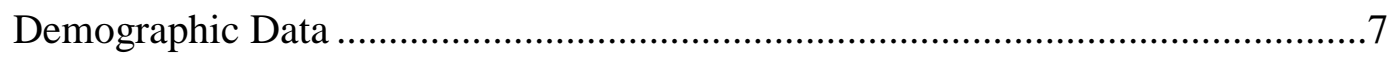

Parental Knowledge of Concussion Pre-Intervention......................................

Educational Intervention and Impact on Concussion Knowledge .......................10

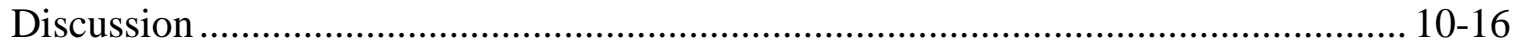

Clinical Relevance ............................................................................. 13

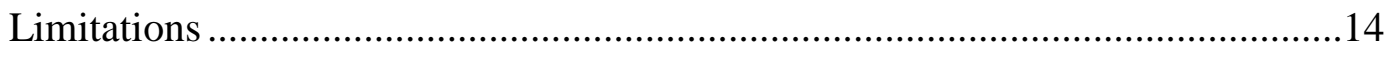

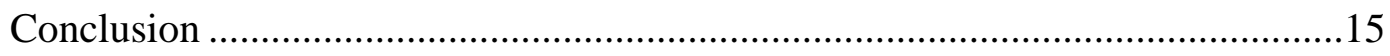

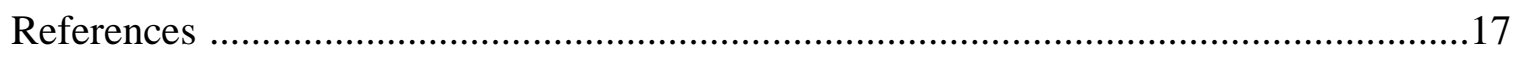

\section{List of Tables and Figures}

Table 1 Parent Sample Characteristics .................................................................27

Table 2 Pre and Post-Intervention Knowledge of Concussion ........................................28

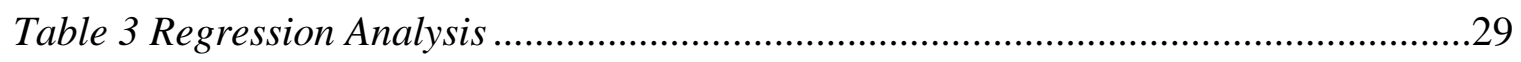

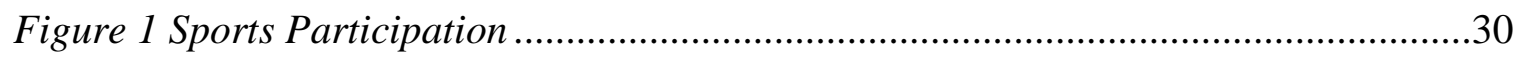

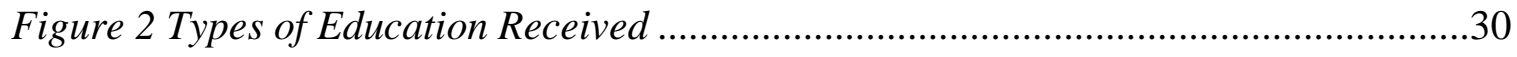




\section{Introduction}

Often referred to as the invisible injury, concussion with its hidden nature is difficult to detect and diagnose. Concussions, a form of traumatic injury, are a serious public health concern. ${ }^{11}$ Concussion is a complex pathophysiologic process resulting in neuropathological, functional disturbances rather than a structural injury to the brain. Concussion cannot be ascertained on traditional neuroimaging tests and is diagnosed solely on clinical findings and physical exam. ${ }^{21,26,29,41,48,56,57,81}$ While most individuals fully recover 7-14 days following injury, the signs and symptoms have physical, cognitive, psychological, and emotional implications that last several minutes to several months and even longer in some cases. ${ }^{23,26,51,55-57,63}$ Symptoms most commonly associated with concussion are headache, dizziness, fatigue, memory and concentration problems, irritability, sleep and mood disturbances, and balance impairments. ${ }^{3,11,54-}$ ${ }^{56}$ Concussion can occur in any youth sport activity, and concussion rates are on the rise with approximately 1.6 to 3.8 million sports-related concussions each year. ${ }^{7,10,15,19,26,31,33,44,50,72}$ There are an estimated 45 million American youth who participate in organized or recreational nonscholastic sports yearly. ${ }^{65}$ Youth athletes 5-18 years of age account for $65 \%$ of sports and recreational traumatic brain injury, including concussion, treated in US emergency departments annually. ${ }^{10,11}$

With participation in youth sports at an all-time high ${ }^{62}$ and the prevalence of sportsrelated concussion higher in children than adults, ${ }^{4,19,30}$ the commonality of concussion in the pediatric population results in a potential for significant acute and long-term complications on youth neurodevelopment. A single concussion suffered in childhood in rare cases has been linked to long term and permanent disabilities, and multiple concussions have particularly severe consequences. ${ }^{26,35,58,59}$ A child who suffers one concussion is four to six times more likely to suffer a subsequent concussion. ${ }^{8,28,39}$ The youth athlete should be managed more conservatively 
secondary to longer recovery times, possible long term effects, and potential catastrophic effects of early return to play such as Second Impact Syndrome (SIS), which in rare cases can result in death. ${ }^{35,36,58}$ It is therefore critical that individuals involved in youth sports, parents in particular, can recognize concussion signs and symptoms in a timely manner to ensure proper concussion management as these symptoms can have long term effects on a child's thinking, memory, learning, language, and emotions. ${ }^{17,26,33,45,56,63,74,84}$ Yet, it is estimated that $50 \%-70 \%$ of sportrelated concussions go unreported and undetected. ${ }^{14,52,59,83}$ Underreporting is a product of a lack of knowledge, and poor awareness of concussion is a significant barrier to proper identification and management of concussion injuries. ${ }^{12,14,52,59,83}$

Legislatures across the United States have developed policies to protect youth athletes in response to the prevalence of concussive injury and increasing numbers of catastrophic outcomes. ${ }^{25}$ As early as 2014, all 50 states and the District of Columbia had passed concussion laws designed to protect the youth athlete, requiring that athletes be removed from play and cleared by a licensed healthcare provider before being allowed to return to practice or competition. Legislation has been targeted at coaches, parents, and athletes to promote safety, concussion knowledge, and awareness in youth scholastic sports. ${ }^{20}$ However, a majority of concussion laws in place only address concussion and return to play practice standards for the "interscholastic athlete." An interscholastic athlete is any athlete who is participating in athletics at the school level, typically high school or middle school, whereas a club sport is any activity involving physical exertion and skill in which an individual or team competes against another but that is not organized by a school system. Most legislative efforts do not apply to children participating outside of school sanctioned sporting events, thus leaving youth participating in club and other recreational sporting events at increased risk for catastrophic injury. ${ }^{46}$ 
Many state laws focus on parental knowledge and awareness of concussion because parents play a key role in recognizing and seeking treatment for their child..$^{5,13,45,49,62,74,75} \mathrm{~A}$ majority of youth club sports teams and organizations are manned by volunteer coaches without on-site physicians or athletic trainers. ${ }^{73,82}$ Several studies have demonstrated gaps in knowledge, identification, and management of concussion among athletes, coaches, physicians, and athletic trainers. ${ }^{17,32,38,48,61,64,73}$ Therefore, it is imperative that parents be aware of the dangers of sustaining a concussion and knowledgeable of concussion signs and symptoms. ${ }^{14,45,52,73}$

The first and most important step in concussion management is recognition that an injury has occurred. ${ }^{17,52-55}$ In the absence of medical personnel on-site for most club sports activities, parents and coaches must recognize that a concussion has occurred. ${ }^{45,49,75}$ Parents of youth play a significant role in identification and management of sport-related concussion, but are often unaware of the consequences of concussion and lack knowledge and ability to recommend concussion management. ${ }^{13,40,43,45,73,75}$ Studies examining parental knowledge and awareness of sports-related concussion have demonstrated critical deficiencies. ${ }^{5,13,17,18,32,43,45,49,64,67,73-75,77,79,80}$ A majority parents (50-75\%) failed to recognize that concussion was a mild traumatic brain injury, and up to $80 \%$ were unaware of medical clearance requirements for return to play. ${ }^{18,32,43,49,64,73,75,79,80}$ Parents of youth athletes demonstrated difficulty discerning between correct and incorrect concussion signs and symptoms, missed difficulty falling asleep, increased emotion/irritability, mood alterations, and disorientation as common concussion signs and symptoms, and failed to recognize persistent symptoms associated with postconcussion. . $^{13,17,37,49,67,74,77}$

In an effort to reduce injury, raise public awareness, and provide education in response to the Children's Health Act of 2000 (H.R. 4365) (Library of Congress, 1999-2000), the Centers for 
Disease Control and Prevention's National Center for Injury Prevention and Control (CDC) launched the "HEADS UP" national education initiative in 2003. The goal of this initiative was to protect people of all ages, especially children and teens, from the effects of concussion and other serious brain injuries. ${ }^{9,11}$ The Heads Up initiative included easy-to-follow educational fact sheets, booklets, wallet cards, clipboard stickers, and videos for educating youth sport coaches, parents, and athletes. ${ }^{5,11,16,36,71}$ Studies to evaluate this CDC educational initiative found the program to be effective overall. Coaches who utilized the toolkits reported being better able to identify athletes who have a concussion, taking concussions more seriously, and learning something new about concussion. When coaches were asked which materials they planned on using in the future, the educational video and parent's fact sheet were most reported. ${ }^{16,71}$ When the materials, originally designed for use with coaches, were modified to address a small group of parents, evidence of a positive impact on perception and awareness of concussion was reported. $^{47}$

Youth are playing more sports at more intense levels with increased risk for serious injury, yet parents' concerns have not risen similarly. ${ }^{34}$ Concussion laws and regulations are narrow in practice and apply only to school sanctioned interscholastic youth sporting events. Studies have explored the effects of parental knowledge on early concussion detection, management, and effectiveness of educational initiatives. Research to date has generally involved small numbers of participants, few sports, and narrow geographic representation. ${ }^{5,13,32,37,43,45,47,49,62,73-75,77}$ Regardless of severity, concussion is a serious injury with potentially catastrophic, life- altering consequences. Proper concussion identification is a key factor in concussion management and parents play a vital role in concussion identification and treatment adherence. Despite a surge of information, legislative efforts, and media coverage, 
research in the area of improving parental knowledge of sport-related concussion through educational interventions remains limited. The purpose of this study was to (1) investigate current knowledge of concussion among parents whose children age 5-18 years play a club sport and (2) identify the effects on concussion knowledge change of the CDC Concussion Awareness Video compared to the CDC Concussion Fact Sheet for Parents educational interventions.

\section{Methods}

\section{Participants}

Participants were 140 youth club sport parents (101 female, 39 male) from Maryland, Ohio, Pennsylvania, and West Virginia whose children played the following club sports: football, soccer, lacrosse, basketball, hockey, wrestling, baseball, volleyball, softball, cheerleading, gymnastics, swimming, flag football, tennis, equestrian, cross country, archery/air rifle, and dance. Parent participants ranged in age from 29 to 62 years (mean=43.1, SD=6.4 years), were well educated, and affluent. Participant demographics are listed in Table 1.

\section{Measure}

The measure initially was developed utilizing peer reviewed literature and the CDC "Heads Up to Parents" educational initiative. The measure was revised in response to feedback from two survey experts and one content expert, as well as information from a pilot with 24 youth sports parents. The revised measure utilized a 5-point Likert-type response scale, included 53 items measuring concussion knowledge, and demonstrated good internal consistency (Cronbach's Alpha $=0.83$ ). Consistent with previous research, some items required participants

to distinguish appropriately between true and false concussion signs and symptoms. ${ }^{13,37,49}$

\section{Procedures}

Institutional Review Board approval is on file, and all participants viewed informed consent information before completing the online survey pre-intervention. Parents of children 5- 
18 years of age were recruited from club sports organizations identified through an extensive internet search. Emails were sent to over 600 organizations in Maryland, Ohio, Pennsylvania, and West Virginia for distribution to parents of youth athletes. Recruited participants were randomly assigned to either view the 10 minute CDC Concussion Awareness Video published on YouTube (https://www.youtube.com/watch?v=AnYNfj-NZqo) or view the CDC's Concussion Fact Sheet for Parents ${ }^{9}$

(https://www.cdc.gov/headsup/pdfs/custom/headsupconcussion_fact_sheet_for_parents.pdf). Each participant then completed the post-intervention survey. The survey and intervention were embedded so that participants never left a single internet browser window. The survey and intervention took no longer than 30 minutes to complete. The survey was open for 12 weeks with reminders sent at 2 and 4 weeks to boost return rate.

\section{Data Analysis}

Data were recorded through the Qualtrics software (Qualtrics, Provo, UT) and imported into SPSS (SPSS Inc., Chicago, IL) for analyses. Descriptive statistics were used to characterize population attributes, including demographics of both parent and child, previous concussion information received, and pre- and post-intervention concussion knowledge. Hierarchical multiple regression analysis was conducted with predictors entered in blocks to control for their influence on predictors entered in later blocks: pre-intervention knowledge and previous concussion information received entered in block one; age in years, gender, educational attainment, and income entered in block two; and type of educational intervention entered in block 3. Educational level was categorized as a) less than Bachelor degree, b) Bachelor degree, or c) graduate degree / professional degree, and dichotomous predictor variables were created using dummy coding and the lowest category as baseline reference. ${ }^{24}$ Income status was classified as a) less than $\$ 100,000$ or b) $\$ 100,000$ or more. Prior concussion information received 
was calculated as the number of types of information indicated and educational intervention was categorized as either video intervention or print material intervention. Assumptions underlying multiple regression were met (no influential outliers, no multi-collinearity among predictors, homogeneity and normality of residuals), and power analyses indicated the sample size was appropriate to detect a medium effect size. ${ }^{24}$

\section{Results}

\section{Demographic Data}

Demographics for 140 parents whose children played a club sport are provided in Table 1. The mean age of respondents was 41.1 years $(\mathrm{SD}=6.4$; range $=29-62)$ with mothers accounting for $72.1 \%$ of the respondents. The average number of children reported per household was 2.34 children $(\mathrm{SD}=0.89$; range $=1$ to $>5)$ with a mean age of 11.6 years $(\mathrm{SD}=$ 3.3; range $=5-18$ years). All respondents reported graduating from high school or equivalent with $78.6 \%$ attaining a bachelor's degree or higher. Household income ranged from $2.1 \%$ with < $\$ 25 \mathrm{k}$ to $66.4 \%$ with $\geq \$ 100 \mathrm{k}$ (see Table 1 ). Figure 1 shows the club sports in which youth participated. $17.1 \%$ of parents reported that their child had sustained a concussion. Of those who reported a concussion, $5.0 \%$ occurred in soccer, $2.9 \%$ each in football and hockey, $2.1 \%$ in basketball, $1.4 \%$ in baseball, and $0.7 \%$ each in flag football, gymnastics, softball and volleyball.

\section{Parental Knowledge of Concussion Pre-Intervention}

In general, parents demonstrated a moderate level of concussion knowledge prior to the intervention $($ mean $=3.37, \mathrm{SD}=0.26)($ see Table 2$)$. Parents of children who play club sports reported excellent awareness of concussion with $99.3 \%$ reporting agreement to being aware of sport-related concussion. In contrast, only $59.3 \%$ of parents reported being aware of second impact syndrome. Only $44.3 \%$ of parents agreed that they had received information about concussion prior to their child's participation in the club sport with a majority $(54.3 \%)$ reporting 
that the information came from soccer clubs. Of the prior information received, information about concussion signs and symptoms was most reported (44.3\%) followed by a concussion fact sheet $(42.9 \%$ ) (see Figure 2). A small portion of parents (19.3\%) were aware of any type of cognitive pre-testing for their child prior to club sports participation. Of those that were aware, cognitive pre-testing occurred most frequently (49.3\%) in soccer followed by basketball (27.1\%), baseball $(22.1 \%)$, and gymnastics $(20.0 \%)$. Only a little more than half of parents $(56.4 \%)$ were aware of the CDC's "Heads Up: Concussion in Youth Sports" initiative.

Most parents (98.5\%) agree that it is important to be knowledgeable about sports-related concussions while $68.5 \%$ feel that concussions are a critical issue in the club sport their child participates in. Most parents $(89.3 \%)$ reported feeling that they would be able to recognize concussion signs and symptoms in their child, but only half of all parents $(50.7 \%)$ agreed that they would be able to determine when their child was ready to return to sport after suffering a concussion. More than half of parents (57.1\%) either did not know or disagreed as to whether the club organization in which their child participated had a return to play policy and $60 \%$ of parents were unsure or disagreed that their child's coach was trained through the CDC's 'Heads Up" initiative. Most parents (79.9\%) were either unsure or disagreed with knowing the state in which they lived had concussion legislation to protect their child. Not even half of parents $(48.6 \%)$ were confident in their child's coaches' ability to identify concussion. In regards to medical personnel trained to identify concussion, $46.4 \%$ of parents agreed that such personnel were present for competitions and only $19.3 \%$ for practices. Roughly two-thirds of parents $(68.5 \%)$ were aware of online training tools geared toward the parent about sports-related concussions. 
Overall, there was a high level of agreement that concussion is a type of brain injury (98.6\%), that all concussions are serious $(95.7 \%)$, that concussions can occur without a loss of consciousness $(97.9 \%)$ or a blow to the body $(84.3 \%)$, and that concussion can occur in any sport or recreational activity (99.3\%). Almost all parents (95\%) agreed that if a child suffers a concussion, they cannot return to play the same day and should not return to play until they are symptom free. $93.5 \%$ of parents agreed that a loss of consciousness is not necessary for the concussion diagnosis, but $62.9 \%$ were unsure or disagreed that most concussions are preventable. Nearly 20 percent $(17.8 \%)$ of parents were unsure or disagreed that a repeat concussion before recovery from the previous concussion could result in death. A large portion of parents (78.6\%) were unsure or agreed that brain imaging (CT and MRI scans) can be used to diagnose concussion. Nearly half of parents (47.9\%) were unsure or disagreed that a "bell ringer" is the same thing as a concussion, and $19.9 \%$ of parents agreed that symptoms from a concussion will occur right away.

In general, a majority of parents were able to accurately (>90\%) identify 10 of the 16 true concussion signs and symptoms, which included neck pain, sensitivity to light and noise, difficulty concentrating, balance problems, fuzzy or blurred vision, difficulty remembering new information, difficulty thinking, dizziness, nausea/vomiting, and difficulty speaking. True signs and symptoms associated with concussion that were less accurately identified by parents included feeling tired/no energy $(82.2 \%)$, headaches (80\%), change in sleep habits $(78.6 \%)$, mood changes (75.7\%), irritability (71.4\%), and nervousness/anxiety (67.8\%). A large portion of parents $(>75 \%)$ inaccurately rated as a high level of importance false or "red herring" signs and symptoms as indicators they would keep their child out of play and seek medical attention. The "red herring" signs that were rated with a high level of importance included inability to 
swallow (98.6\%), chest pain $(98.6 \%)$, hearing voices $(95.8 \%)$, difficulty with urination $(83.5 \%)$, and lowered pulse rate $(77.1 \%)$. Rated lower but still at a moderately high level of importance were false signs and symptoms of concussion including difficulty with defecation (67.2\%), feelings of euphoria (67.2\%), and sinus congestion (37.8\%).

\section{Educational Intervention and Impact on Concussion Knowledge}

Table 3 displays the results of hierarchical multiple regression on the knowledge of concussion construct to investigate the ability of the CDC's concussion educational interventions to predict parental concussion knowledge after controlling for pre-concussion knowledge, prior concussion information received, income, educational level, gender, and age. In the first block, pre-intervention knowledge and prior concussion information were statistically significant [F (2, $137)=80.06, \mathrm{p}<.0001]$ and explained $58 \%$ of the variance in post-intervention knowledge. The introduction of demographic variables in block 2 (i.e., income, education, gender, age) was significant and explained an additional $4.0 \%$ of variance in post-intervention knowledge of concussion $\left[\mathrm{R}^{2}\right.$ Change $\left.=.04 ; \mathrm{F}(5,132)=2.43, \mathrm{p}<.05\right]$. Of the four predictor variables in block 2 , gender $(\beta=-0.18, \mathrm{p}<0.05)$ was the only statistically significant predictor with female gender related to higher post-intervention concussion knowledge controlling for pre-intervention knowledge, prior concussion information received, income, education, and age. Intervention type (video versus print) in block 3 did not significantly explain additional variance in postintervention concussion knowledge $\left[\mathrm{R}^{2}\right.$ Change $\left.=.00 ; \mathrm{F}(1,131)=0.96, \mathrm{p}>.05\right]$ after controlling for pre-knowledge, prior concussion information received, income, education, gender, and age (see Table 3). There were no other statistically significant effects.

\section{Discussion}

Most parents reported awareness of sports-related concussion as a type of brain injury and an important topic to be knowledgeable about, yet a third reported that concussions were not 
a critical issue. These findings are consistent with previous studies in that parents may demonstrate a moderate to high level of concussion knowledge and awareness, but critical knowledge gaps placing children at risk remain. ${ }^{5,13,37,43,45,47,49,64,75,79,80}$ There is growing evidence to suggest that children are more susceptible than adults to permanent and devastating cortical brain damage, taking longer to recover to baseline neurocognitive status, than their adult counterparts. ${ }^{1,2,4,6,20,22,23,27,33,36,53,62,69,70,76,78,85}$ For example, one study demonstrated the average number of days to return to cognitive baseline was longer for youth 13-16 years than for 18-22 year old athletes in verbal memory, visual memory, reaction time, and post concussive symptoms. ${ }^{4}$

Despite policy changes in all 50 states and a surge in concussion education initiatives, this study found an alarming number of parents did not receive concussion education prior to their child's participation in club sports. Many parents in the study reported that brain imaging (CT and MRI scans) can be used to diagnose concussion, which is a well-documented inaccuracy ${ }^{56}$ and nearly half were unaware that a "bell ringer" is the same thing as a concussion. Very few parents were aware of baseline cognitive testing or a return to play policy in the club their child participated in, and most parents were unaware of legislative policy in their state. This lack of information dissemination and baseline testing puts youth athletes at risk. These findings are consistent with previous literature regarding lack of adherence and implementation of return to play guidelines by club sport organizations. ${ }^{32,43,79}$ In one such study, only $7 \%$ of parents or children reported receiving any type of concussion education or return to play guidelines from their sports organization. ${ }^{32}$

Similar to previous studies, parents in this study demonstrated a general overestimation in regards to both true and false signs and symptoms of concussion. ${ }^{13,37}$ All eight "red herring" 
distractor signs and symptoms were rated as high or higher than signs and symptoms truly associated with concussion. The lowest reported true symptoms of concussion were nervousness/anxiety, irritability, mood changes, change in sleep habits, and headaches. This is consistent with previous findings and clearly warrants educating parents to accurately identify signs and symptoms associated with concussion as this is a primary factor in the identification of concussion. . $^{13,17,37,49,56}$

With children participating in sports at a higher, more intense level than ever before, and considering the time children spend away from home participating in a club sport, confidence in club coaches and organizations would seemingly be of utmost concern. Surprisingly, less than half of parents in this study reported confidence in their child's coach's ability to identify concussion, and even fewer believed their child's coach had any formal concussion training. Parents were unsure and unaware whether there were trained medical staff at either practice or competition who could identify concussion. Only about half of parents in this study had heard of the CDC's "Heads Up: Concussion in Youth Sports" initiative. These findings are consistent with previous studies indicating continued need to educate those involved in youth sports. $5,13,32,43,49,74,79,80$

With the mounting evidence of concussion knowledge gaps in parents of youth athletes, there has been a stark lack of research focused on narrowing knowledge gaps through educational interventions. This study presented parents with one of two (randomized) educational interventions, and knowledge of concussion improved significantly following intervention, albeit the size of that effect was small (Table 2). Knowledge change can occur and knowledge gaps can narrow with education. ${ }^{47}$ By far the greatest predictor of post-intervention knowledge of concussion in parents whose children play a club sport was the level of pre- 
intervention knowledge. This is consistent with other findings in that parents who received concussion information in the past had better overall knowledge. ${ }^{67}$

Gender, as identified in previous studies, ${ }^{13,45}$ was the only demographic variable that was significant in predicting post-intervention knowledge. Females generally had slightly higher post knowledge of concussion scores after controlling for prior knowledge and other demographics. Contrary to previous findings, age, education, and household income did not affect concussion knowledge in parents whose children play club sports. ${ }^{17}$ These findings validate the need for continued outreach and educational initiatives geared toward those involved in youth sports.

\section{Clinical Relevance}

Findings from this study suggest that neither the video intervention nor the online print material was a better predictor of post-knowledge of concussion after controlling for preknowledge and demographics. The interventions were similar in content but delivered in different modalities. There was a small positive effect of intervention on concussion knowledge regardless of intervention type. The lack of larger change in parental knowledge despite intervention could be that the interventions, despite mode of delivery, do not meet the need of the target audience. In this case, the audience was parents, who are adult learners. Andragogy, the method of teaching adults, is based on a core set of principles, few of which were met in this type of intervention. These principles include the learner's need to know, previous experiences, self-concept, readiness to learn, orientation to learning, and motivation. ${ }^{42}$

Adults need to understand the reasoning and the importance of learning something prior to taking on the task of learning. In this case, one-third of parents did not feel that concussions were a critical issue in the sport in which their child participated lending to potential perceived lack of "need to know." The principle of self-concept and orientation to learning is that adults are responsible for their own decisions, capable of self-direction, and motivated to learn to the 
extent that they feel learning will help them with a particular task or situation they may

encounter in everyday life. ${ }^{42}$ Many of the current concussion education programs, including the ones in this study, consist of presenting the learner with material that is to be synthesized and "learned" in a context that violates many of the principles of adult learning. Presentation of written material or requiring an individual to view a video is a passive attempt to educate about a very important topic. One single approach to teaching does not work for most learners and this type of education eliminates active participation, which has been shown to help learners integrate important information. ${ }^{42}$

Improving concussion educational interventions to meet the core principles of adult education would ultimately improve the outcome of learning. Presenting parents with objective and concrete information as to why knowledge of concussion is important would assist with the adults learners "need to know" instead of passive presentation of material without knowledge of importance. The learning experience should provide enough time for synthesis of the material but also allow for the learners active participation in a multifaceted approach to learning. Providing structure but allowing for flexibility in the learning environment is crucial in that it allows for balance between the learners responsibilities and self-concept to readiness to learn. Successful adult educational programs tap into the experiences of the learner and employ strategies to encourage application of new information through techniques including group discussions, simulation exercises, case study methodology, and problem solving activities. ${ }^{42}$

\section{Limitations}

Limitations of this study include the brevity and somewhat narrow scope of intervention focused on parental concussion knowledge, inability to assess maintenance of knowledge change over time beyond immediate post-intervention, limited geographic region across four states in 
the US, and modest sample size given hundreds of thousands of participants in youth club sports through the year across the United States.

Despite these limitations, this study is an extension of several previous studies. There is sufficient evidence that parents lack concussion knowledge. Consistent with previous findings, this study confirms dangerous concussion knowledge gaps in parents of youth athletes, but it identifies areas of concern in concussion education. Many of the previous studies recommend continued education for the lack of parental knowledge but stop there without examining concussion intervention effectiveness. This study takes previous findings a step further, examining knowledge gaps in parents whose children play club sports and studies the effectiveness of concussion interventions on the identified gaps in knowledge.

\section{Conclusion}

This study confirms the presence of gaps in knowledge of concussion in parents whose children play club sports. Without the protection of concussion legislation, those athletes who participate in club sports are at particular risk due to lack of concussion knowledge and education. This study identified critical deficiencies in need of immediate improvement for those who are involved in club sports. However, this study confirms that education can have a positive impact on parental knowledge of concussion. Pre-knowledge of concussion is the greatest predictor of post-concussion knowledge, therefore pre-assessment of target audience knowledge followed by a custom educational intervention taking into account principles of adult learning may be the best way to increase parental concussion knowledge. Interventions should utilize teaching strategies targeted to adult learners and allow time for reflection and discussion to facilitate assimilation of new information. Concussion policy content should be included regardless of mode of delivery as most concussion educational initiatives are deficient in this 
content area. Further investigation of educational intervention mode of delivery is warranted, but education is the key to protecting youth who participate in sports at the club level. 


\section{References}

1. Anderson V, Moore C. Age at injury as a predictor of outcome following pediatric head injury: A longitudinal perspective. Child Neuropsychology. 1995; 1(3):187-202.

2. Anderson VA, Morse SA, Klug G, et al. Predicting recovery from head injury in young children: a prospective analysis. J Int Neuropsychol Soc. 1997; 3(6):568-80.

3. Aubry M, Cantu R, Dvorak J et al. Summary and agreement statement of the first International Conference on Concussion in Sport, Vienna 2001. Recommendations for the improvement of safety and health of athletes who may suffer concussive injuries. $\mathrm{Br} J$ Sports Med. 2002 Feb; 36(1):6-10.

4. Baillargeon A, Lassonde M, Leclerc S, Ellemberg D. Neuropsychological and neurophysiological assessment of sport concussion in children, adolescents and adults. Brain Inj. 2012; 26(3):211-20.

5. Bloodgood B, Inokuchi D, Shawver W et al. Exploration of awareness, knowledge, and perceptions of traumatic brain injury among American youth athletes and their parents. $J$ Adolesc Health. 2013;53(1):34-9.

6. Boutin D, Lassonde M, Robert M, Vanassing P, Ellemberg D. Neurophysiological assessment prior to and following sports-related concussion during childhood: a case study. Neurocase, 2008; 14(3): 239-248.

7. Buzas D, Jacobson NA, Morawa LG. Concussions from 9 youth organized Sports Results from NEISS Hospitals over an 11-Year Time Frame, 2002-2012. Orthop J Sports Med. 2014;2(4):2325967114528460. doi: 10.1177/2325967114528460.

8. Cantu RC. Posttraumatic retrograde and anterograde amnesia: pathophysiology and implications in grading and safe return to play. J Athl Train. 2001;36(3):244-248. 
9. Centers for Disease Control and Prevention Web site. HEADS UP to Parents. https://www.cdc.gov/headsup/parents/index.html. Updated April 29, 2016. Accessed May $21,2016$.

10. Centers for Disease Control and Prevention. Nonfatal traumatic brain injuries related to sports and recreation activities among persons aged $\leq 19$ years---United States, 2001-2009. MMWR: Morbidity and mortality weekly report. 2001;60(39):1337-1342.

11. Centers for Disease Control and Prevention Web site. Basic Information about Traumatic Brain Injury and Concussion. https://www.cdc.gov/traumaticbraininjury/basics.html. Updated January 22, 2017. Access May 21, 2017.

12. Chrisman SP, Quitiquit C, Rivara FP. Qualitative study of barriers to concussive symptom reporting in high school athletics. J Adolesc Health. 2013;52(3):330-335.

13. Coghlin CJ, Myles BD, Howitt SD. The ability of parents to accurately report concussion occurrence in their bantam-aged minor hockey league children. J Can Chiropr Assoc. 2009;53(4):233-250.

14. Collins MW, Iverson GL, Lovell MR, McKeag DB, Norwig J, Maroon J. On-field predictors of neuropsychological and symptom deficit following sports-related concussion. Clin J Sport Med. 2003;13(4):222-229.

15. Conder RL, Conder AA. Sports-related concussions. N C Med J. 2015;76(2):89-95.

16. Covassin T, Elbin RJ, Sarmiento K. Educating coaches about concussion in sports: evaluation of the CDC's "Heads Up: concussion in youth sports" initiative. J Sch Health. 2012;82(5):233-238. 
17. Cusimano MD, Zhang S, Topolovec-Vranic J, Hutchison MG, Jing R. Factors affecting the concussion knowledge of athletes, parents, coaches, and medical professionals. SAGE Open Med. 2017;5:2050312117694794. doi: 10.1177/2050312117694794.

18. C.S. Mott Children's Hospital Web site. Concussions in school sports: parents illprepared for role in reducing kid's risks. National Poll on Children's Health. http://mottnpch.org/reports-surveys/concussions-school-sports-parents-ill-prepared-rolereducing-kid\%E2\%80\%99s-risks. Published June 14, 2010. Accessed May 1, 2016.

19. Daneshvar DH, Nowinski CJ, McKee AC, Cantu RC. The epidemiology of sport-related concussion. Clin Sports Med. 2011;30(1):1-17.

20. Doolan AW, Day DD, Maerlender AC, Goforth M, Gunnar Brolinson P. A review of return to play issues and sports-related concussion. Ann Biomed Eng. 2012;40(1):106113.

21. Edwards JC, Bodle JD. Causes and consequences of sports concussion. J Law Med Ethics. 2014;42(2):128-132.

22. Ewing-Cobbs L, Miner ME, Fletcher JM, Levin HS. Intellectual, motor, and language sequelae following closed head injury in infants and preschoolers. J Pediatr Psychol. $1989 ; 14(4): 531-547$.

23. Field M, Collins MW, Lovell MR, Maroon J. Does age play a role in recovery from sports-related concussion? A comparison of high school and collegiate athletes. $J$ Pediatr. 2003;142(5):546-553.

24. Field A. Discovering statistics using SPSS. Regression. $3^{\text {rd }}$ ed. Thousand Oaks: Sage publications; 2009:197-263. 
25. Faure C. Creating concussion management policy: how school leaders, coaches and parents can work together to ensure kids stay safer in sport. American Secondary Education. 2010; 5-14.

26. Giza CC, Kutcher JS. An introduction to sports concussions. Continuum (Minneap Minn). 2014;20(6 Sports Neurology):1545-51. doi:

10.1212/01.CON.0000458975.78766.11.

27. Gronwall D, Wrightson P, McGinn V. Effect of mild head injury during the preschool years. J Int Neuropsychol Soc. 1997;3(6):592-597.

28. Guskiewicz KM, McCrea M, Marshall SW et al. Cumulative effects associated with recurrent concussion in collegiate football players: the NCAA Concussion Study. Jama. 2003;290(19), 2549-2555.

29. Guskiewicz KM, Teel E. Clinical Management of Sport-Related Concussion: Developing a Roadmap to a Successful Outcome. Kinesiology Review. 2015;4: 156-168.

30. Halstead ME, Walter KD. American Academy of Pediatrics. Clinical report--sport-related concussion in children and adolescents. Pediatrics. 2010;126(3):597-615.

31. Hanson E, Stracciolini A, Mannix R, Meehan WP. Management and prevention of sportrelated concussion. Clin Pediatr. 2014;53(13):1221-1230.

32. Haran HP, Bressan S, Oakley E, Davis G, Anderson V, Babl FE. On-field management and return-to-play in sports-related concussion in children: are children managed appropriately? J Sci Med Sport. 2016;19(3):194-199.

33. Harmon KG, Drezner JA, Gammons M et al. American Medical Society for Sports Medicine position statement: concussion in sport. Br J Sports Med. 2013;47(1):15-26. 
34. Hart Research Associates. (2011). A national survey of parent' knowledge, attitudes, and self-reported behaviors concerning sports safety. Retrieved May 1, 2016 from https://www.safekids.org/research-report/national-survey-parents-attitudes-and-selfreported-behaviors-concerning-sports.

35. Jacobson NA, Buzas D, Morawa LG. Concussions from youth football results from NEISS hospitals over an 11-year time frame, 2002-2012. Orthop J Sports Med. 2013;1(7):1-6.

36. Karlin AM. Concussion in the pediatric and adolescent population: "different population, different concerns". PM R. 2011;3(10 Suppl 2):S369-79.

37. Kay MC, Register-Mihalik JK, Ford CB, Williams RM, Valovich McLeod TC. Parents' and Child's Concussion History as Predictors of Parental Attitudes and Knowledge of Concussion Recognition and Response. Orthop J Sports Med. 2017;5(12):1-11.

38. Kearney PE, See J. Misunderstandings of concussion within a youth rugby population. $J$ Sci Med Sport. 2017;20(11):981-985.

39. Kelly JP, Rosenberg JH. Diagnosis and management of concussion in sports. Neurology. 1997;48(3): 575-580.

40. Kerr ZY, Zuckerman SL, Wasserman EB, Covassin T, Djoko A, Dompier TP. Concussion symptoms and return to play time in youth, high school, and college American football athletes. JAMA Pediatr. 2016;170(7):647-653.

41. King D, Brughelli M, Hume P, Gissane C. Assessment, management and knowledge of sport-related concussion: systematic review. Sports Med. 2014;44(4):449-471.

42. Knowles MS, Holton EF, Swanson RA. The adult learner. Burlington, MA: Elsevier; 2011. 
43. LaBond V, Barber KR, Golden IJ. Sports-related head injuries in students: parents' knowledge, attitudes, and perceptions. NASN Sch Nurse. 2014;29(4):194-199.

44. Langlois JA, Rutland-Brown W, Wald MM. The epidemiology and impact of traumatic brain injury: a brief overview. J Head Trauma Rehabil. 2006;21(5): 375-378.

45. Lin AC, Salzman GA, Bachman SL et al. Assessment of parental knowledge and attitudes toward pediatric sports-related concussions. Sports Health. 2015;7(2): 124-129.

46. Lowrey KM, Morain SR. State experiences implementing youth sports concussion laws: challenges, successes, and lessons for evaluating impact. J Law Med Ethics. 2014;42(3):290-296.

47. Macdonald I, Hauber R. Educating Parents on Sports-Related Concussions. J Neurosci Nurs. 2016;48(6):297-302.

48. Mann A, Tator CH, Carson JD. Concussion diagnosis and management: Knowledge and attitudes of family medicine residents. Can Fam Physician. 2017;63(6):460-466.

49. Mannings C, Kalynych C, Joseph MM, Smotherman C, Kraemer DF. Knowledge assessment of sports-related concussion among parents of children aged 5 years to 15 years enrolled in recreational tackle football. J Trauma Acute Care Surg. 2014;77(3 Suppl 1):S18-22.

50. Marar M, McIlvain NM, Fields SK, Comstock RD. Epidemiology of concussions among United States high school athletes in 20 sports. Am J Sports Med. 201240(4):747-755.

51. McCrea M, Guskiewicz KM, Marshall SW et al. Acute effects and recovery time following concussion in collegiate football players: the NCAA Concussion Study. JAMA. 2003;290(19):2556-2563. 
52. McCrea M, Hammeke T, Olsen G, Leo P, Guskiewicz K. Unreported concussion in high school football players: implications for prevention. Clin J Sport Med. 2004;14(1):13-17.

53. McCrory P, Collie A, Anderson V, Davis G. Can we manage sport related concussion in children the same as in adults? Br J Sports Med. 2004;38(5):516-519.

54. McCrory P, Johnston K, Meeuwisse W et al. Summary and agreement statement of the 2nd International Conference on Concussion in Sport, Prague 2004. Br J Sports Med. 2005;39(4):196-204.

55. McCrory P, Meeuwisse W, Johnston K et al. Consensus Statement on Concussion in Sport: the 3rd International Conference on Concussion in Sport held in Zurich, November 2008. Br J Sports Med. 2009 May;43 Suppl 1:i76-90.

56. McCrory P, Meeuwisse WH Aubry M et al. Consensus statement on concussion in sport: the 4th International Conference on Concussion in Sport held in Zurich, November 2012. Br J Sports Med. 2013;47(5), 250-258.

57. McCrory P, Meeuwisse W, Dvořák J et al. Consensus statement on concussion in sportthe 5th international conference on concussion in sport held in Berlin, October 2016. $\mathrm{Br} J$ Sports Med. 2017;51(11):838-847.

58. McLendon LA, Kralik SF, Grayson PA, Golomb MR. The controversial second impact syndrome: a review of the literature. Pediatr Neurol. 2016;62:9-17.

59. Meehan WP III, Mannix RC, O’Brien MJ, Collins MW. The prevalence of undiagnosed concussions in athletes. Clin J Sport Med. 2013;23(5):339-342.

60. Merriam Webster's Collegiate Dictionary. $10^{\text {th }}$ ed. Springfield: Merriam-Webster; 1993. Club, Sport: 218, 1137. 
61. Miyashita TL, Diakogeorgiou E, Hellstrom B, Kuchwara N, Tafoya E, Young L. High school athletes' perceptions of concussion. Orthop J Sports Med. 2014;2(11):2325967114554549. doi: 10.1177/2325967114554549

62. Moser RS, Schatz P, Jordan BD. Prolonged effects of concussion in high school athletes. Neurosurgery. 2005;57(2):300-306.

63. Mullally WJ. Concussion. Am J Med. 2017;130(8):885-892.

64. Nanos KN, Franco JM, Larson D, Mara K, Laskowski ER. Youth sport-related concussions: perceived and measured baseline knowledge of concussions among community coaches, athletes, and parents. Mayo Clin Proc. 2017;92(12):1782-1790.

65. National Council of Youth Sports. Reports on trends and participation in organized youth sports 2008. http://www.ncys.org/publications/2008-sports-participation-study.php. Updated 2008. Accessed March 15, 2016 from,

66. Nybo T, Koskiniemi M. Cognitive indicators of vocational outcome after severe traumatic brain injury (TBI) in childhood. Brain Inj. 1999;13(10):759-766.

67. Piasek CZ. Parental Misconceptions Regarding Sports-Related Concussion. In 2014 AAP National Conference and Exhibition. American Academy of Pediatrics; Oct 2014.

68. Pfister T, Pfister K, Hagel B, Ghali WA, Ronksley PE. The incidence of concussion in youth sports: a systematic review and meta-analysis. Br J Sports Med. 2016;50(5):292297.

69. Purcell L, Harvey J, Seabrook JA. Patterns of recovery following sport-related concussion in children and adolescents. Clin Pediatr. 2016;55(5):452-458. 
70. Sady MD, Vaughan CG, Gioia GA. School and the concussed youth: recommendations for concussion education and management. Phys Med Rehabil Clin N Am. 2011;22(4):701-719.

71. Sarmiento K, Mitchko J, Klein C, Wong S. Evaluation of the Centers for Disease Control and Prevention's concussion initiative for high school coaches: "Heads Up: Concussion in High School Sports". J Sch Health. 2010;80(3):112-118.

72. Selassie AW, Wilson DA, Pickelsimer EE, Voronca DC, Williams NR, Edwards JC. Incidence of sport-related traumatic brain injury and risk factors of severity: a populationbased epidemiologic study. Ann Epidemiol. 2013;23(12):750-756.

73. Shenouda C, Hendrickson P, Davenport K, Barber J, Bell KR. The effects of concussion legislation one year later-what have we learned: a descriptive pilot survey of youth soccer player associates. PM R. 2012;4(6):427-435.

74. Stevens PK, Penprase B, Kepros JP, Dunneback J. Parental recognition of post concussive symptoms in children. J Trauma Nurs. 2010;17(4):178-182.

75. Sullivan SJ, Bourne L, Choie S et al. Understanding of sport concussion by the parents of young rugby players: a pilot study. Clin J Sport Med. 2009;19(3):228-230.

76. Taylor HG, Alden J. Age-related differences in outcomes following childhood brain insults: an introduction and overview. J Int Neuropsychol Soc. 19973(6):555-567.

77. Thomas DG, Bradley L, Servi A et al. Parental Knowledge and Recall of Concussion Discharge Instructions. J Emerg Nurs. 2018;44(1):52-56.

78. Thompson NM, Francis DJ, Stuebing KK et al. Motor, visual-spatial, and somatosensory skills after closed head injury in children and adolescents: A study of change. Neuropsychology. 1994;8(3). 333. 
79. Turner RW, Lucas JW, Margolis LH, Corwell BN. A preliminary study of youth sport concussions: Parents' health literacy and knowledge of return-to-play protocol criteria. Brain Inj. 2017;31(8):1124-1130.

80. Weerdenburg K, Schneeweiss S, Koo E, Boutis K. Concussion and its management: what do parents know? Paediatr Child Health. 2016;21(3):e22-6.

81. West TA, Marion DW. Current recommendations for the diagnosis and treatment of concussion in sport: a comparison of three new guidelines. J Neurotrauma. 2014;31(2):159-168.

82. Wiersma LD, Sherman CP. Volunteer youth sport coaches' perspectives of coaching education/certification and parental codes of conduct. Res Q Exerc Sport. 2005 Sep;76(3):324-38

83. Williamson IJ, Goodman D. Converging evidence for the under-reporting of concussions in youth ice hockey. Br J Sports Med. 2006;40(2):128-32.

84. Williamson RW, Gerhardstein D, Cardenas J, Michael DB, Theodore N, Rosseau N. Concussion 101: the current state of concussion education programs. Neurosurgery. 2014;75 Suppl 4:S131-5.

85. Zuckerman S, Lee Y, Odom M, Solomon G, Forbes J, Sills A. Recovery from sportsrelated concussion: days to return to neurocognitive baseline in adolescents versus young adults. Surg Neurol Int. 2012;3:130. 
Table 1

Parent Sample Characteristics $(n=140)$

Demographic Characteristic

Statistic

Parent age in years

Range

29-62

Mean (SD)

$43.1(6.4)$

Child age in years

Range

5-18

Mean (SD)

$11.61(3.33)$

Mean (SD) number of children

$2.34(0.89)$

Relationship to child

Mother

$\mathrm{N}(\%)$

Father

$101(72.1)$

39 (27.9)

Number of Children per Parent

1

2

3

4

5

$>5$

18 (12.9)

$73(52.1)$

$37(26.4$

$9(6.4)$

$2(1.4)$

$1(0.7)$

Education

High school/GED

$3(2.1)$

Associate or Technical degree

$27(19.3)$

Bachelor degree

47 (33.6)

Graduate/professional degree

63 (45)

Annual Household Income

$\begin{array}{ll}<\$ 24,999 & 2(1.4) \\ \$ 25,000 \text { to } \$ 49,999 & 8(5.7) \\ \$ 50,000 \text { to } \$ 99,999 & 37(26.4) \\ \$ 100,000 \text { or more } & 93(66.4)\end{array}$


Table 2

Pre and Post-Intervention Knowledge of Concussion

Pre-intervention Post-intervention Cohen's d Cronbach's

Scale Mean (SD) Scale Mean (SD) Alpha

$\begin{array}{lllll}\text { Knowledge of } & 3.73(0.26) & 3.87(0.25) & 0.54^{*} & 0.83\end{array}$

Concussion

$* \mathrm{p}<0.05$ 
Table3

Regression Analysis

\begin{tabular}{|c|c|c|c|}
\hline & \multicolumn{3}{|c|}{ Knowledge of Concussion } \\
\hline & $\Delta \mathrm{R}^{2}$ & $\mathrm{~F}$ & $\beta$ \\
\hline Block 1 & $0.58 * *$ & 94.69 & \\
\hline Pre Knowledge & & & $0.69 *$ \\
\hline Prior Information & & & $0.14^{*}$ \\
\hline Block 2 & $0.04^{*}$ & 2.43 & \\
\hline Income & & & 0.06 \\
\hline Bachelor & & & 0.02 \\
\hline Graduate & & & -0.05 \\
\hline Gender & & & $-0.18^{*}$ \\
\hline Age & & & 0.10 \\
\hline Block 3 & 0.00 & 0.96 & \\
\hline Intervention type & & & 0.05 \\
\hline
\end{tabular}




\section{Sports Participation}

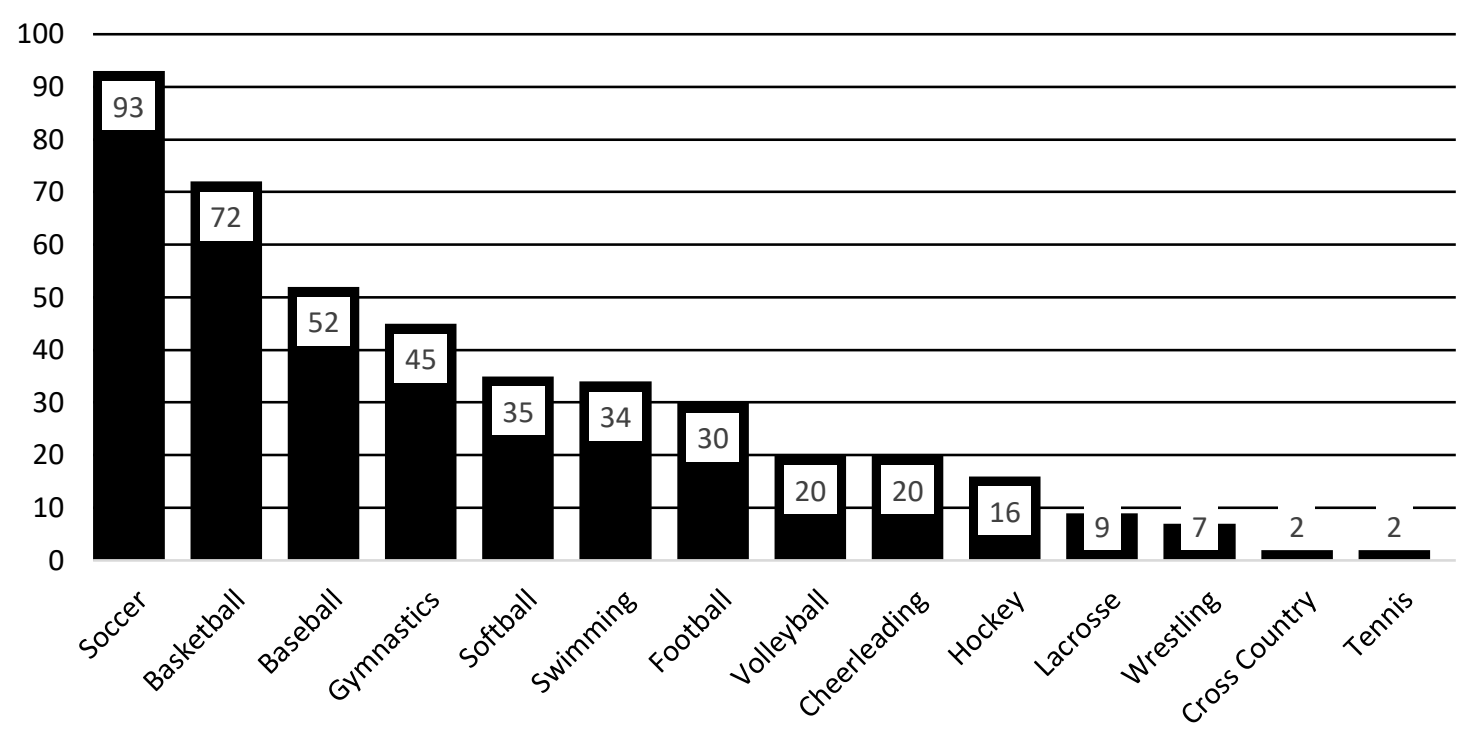

Figure 1: Sports participation as reported by parents (note: $n>140$ secondary to children playing multiple sports)

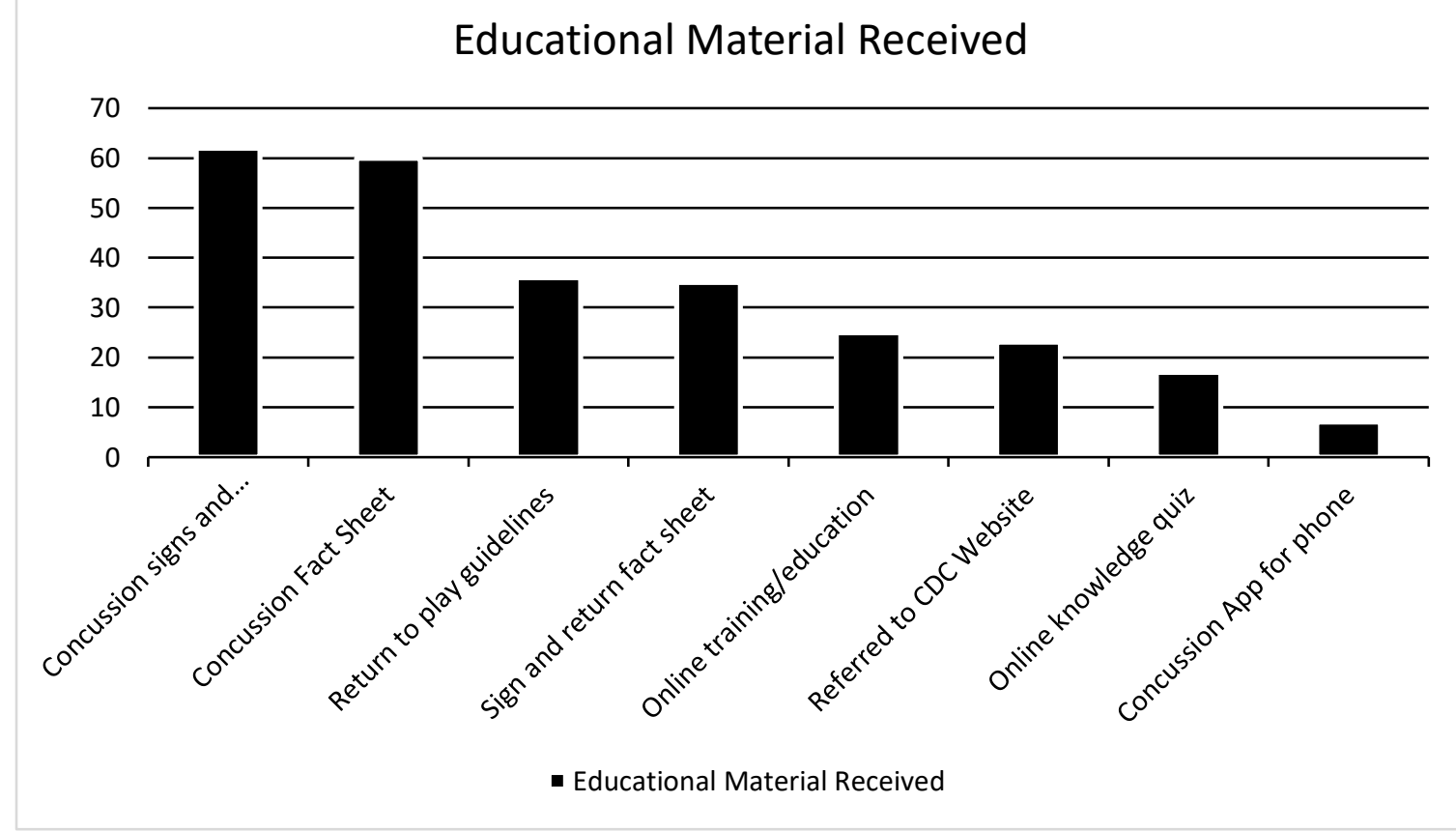

Figure 2: Types of educational material received prior to child's sport participation. (note: $\mathrm{n}>$ 140 secondary to children playing multiple sports) 